\title{
Concurrent Inverted Papilloma and Squamous Cell Carcinoma with Intradural Extension Presenting with Frontal Lobe Syndrome
}

\author{
Abdul Jaleel ${ }^{1}$ Pavithran V. M. ${ }^{1} \quad$ Shanavas Cholakkal ${ }^{1}$ Vineeth Kadangot Kuthampulli ${ }^{1}$ \\ ${ }^{1}$ Department of Neurosurgery, Government Medical College, \\ Kozhikode, Kerala, India \\ Address for correspondence Vineeth Kadangot Kuthampulli, MS, \\ MCh, Department of Neurosurgery, Government Medical College, \\ Kozhikode, Kerala 673008, India (e-mail: kkvine223@gmail.com).
}

Indian J Neurosurg 2022;11:83-85

\begin{abstract}
Inverted papilloma is an uncommon tumor mostly arising from the lateral wall of the nasal cavity and displays a benign but locally aggressive behavior. Intracranial extension is an extremely rare presentation of inverted papilloma. Extension occurs either as a benign lesion or due to malignant transformation. We report a case of concurrent inverted papilloma and squamous cell carcinoma presenting with epistaxis and recent-onset altered behavior and memory impairment. After literature review of similar cases having inverted papilloma with intracranial extension, we could identify a total of 12 cases, most of which were recurrences of a primary inverted papilloma that were resected before extension into the cranial cavity. Most cases were of extradural

Keywords

- inverted papilloma

- intradural extension

- frontal lobe syndrome extension, and intradural spread resulted in poor prognosis on follow-up. Concurrent inverted papilloma and squamous cell carcinoma extending into the anterior cranial fossa and frontal lobe is a very rare clinical entity and can present as frontal lobe syndrome.
\end{abstract}

\section{Key Messages}

Concurrent inverted papilloma and squamous cell carcinoma extending into the anterior cranial fossa and frontal lobe is a very rare clinical entity and can present as frontal lobe syndrome.

\section{Introduction}

Inverted papilloma (IP) is a benign sinonasal epithelial neoplasm arising from the ectodermal Schneiderian membrane. ${ }^{1}$ The correct etiology of IP is unknown, although either chronic inflammation or human papillomavirus (HPV) has been inconsistently associated with IP. ${ }^{2}$

Sinonasal papillomas were first described by Ward and Billroth in the 1850s and later by Ringhertz based on the histological features. Although IP is a tumor of benign entity, it can be locally aggressive eroding adjacent bone, orbit or intracranial cavity. ${ }^{1,3-5}$

Schneiderian papilloma may progress to carcinoma in approximately $10 \%$ of cases. Local recurrence is also common. It may be exophytic or inverted. ${ }^{3}$ IPs have the highest risk of malignant transformation. The presence of obvious keratosis in an inverted Schneiderian papilloma seems to be the histological predictor of malignancy.

\section{Case History}

A 60-year-old gentleman, hailing from North Kerala, with no comorbidities, presented with recent-onset altered behavior, impairment of recent and remote memory, and inappropriate speech of 2 weeks duration. He had recent-onset dramatic changes in behavior, with impulsivity, loss of inhibition, emotional liability, decreased motivation, reduced
DOI https://doi.org/ 10.1055/s-0040-1721561 ISSN 2277-954X.
(C) 2021. Neurological Surgeons' Society of India.

This is an open access article published by Thieme under the terms of the Creative Commons Attribution-NonDerivative-NonCommercial-License, permitting copying and reproduction so long as the original work is given appropriate credit. Contents may not be used for commercial purposes, or adapted, remixed, transformed or built upon. (https://creativecommons.org/licenses/by-nc-nd/4.0/).

Thieme Medical and Scientific Publishers Pvt. Ltd. A-12, 2nd Floor, Sector 2, Noida-201301 UP, India 
verbal output, behavioral slowness, difficulties in planning/ problem solving, and difficulty in social interactions. He also had on and off holocranial headache for the past few months. On consulting an otorhinolaryngologist nearby, right nasal lesion was visualized and an incision biopsy was performed, which revealed IP.

Three days later, he had an episode of severe epistaxis, which was controlled by nasal packing from a local hospital. He presented to us with the aforementioned symptoms and was evaluated with computed tomography (CT) of the head with paranasal sinus (PNS) and magnetic resonance imaging (MRI) of the brain with PNSs.

MRI was suggestive of a lobulated mass lesion extending from the lateral wall of the right nasal cavity extending along the ethmoid sinus and cribriform plate into the anterior cranial fossa. It further extended intradurally, producing a mass effect on the base of both frontal lobes with associated perilesional edema ( $\boldsymbol{- F i g . 1}$ ).

He underwent endoscopic endonasal removal of nasal part of the lesion followed by frontal craniotomy and excision ( - Fig. 2A). Anterior cranial fossa repair was also performed.

Histopathological report suggested squamous cell carcinoma with areas of IP. ( $\mathbf{- F i g}$. 2B). His postoperative period and outpatient department follow-up after 1 month were uneventful.

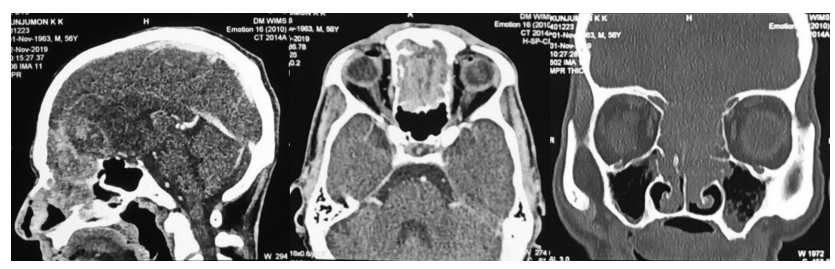

Fig.1 CT head and CT-PNS showing a lobulated mass lesion extending from the lateral wall of the right nasal cavity extending along the ethmoid sinus and cribriform plate into the frontal lobe.
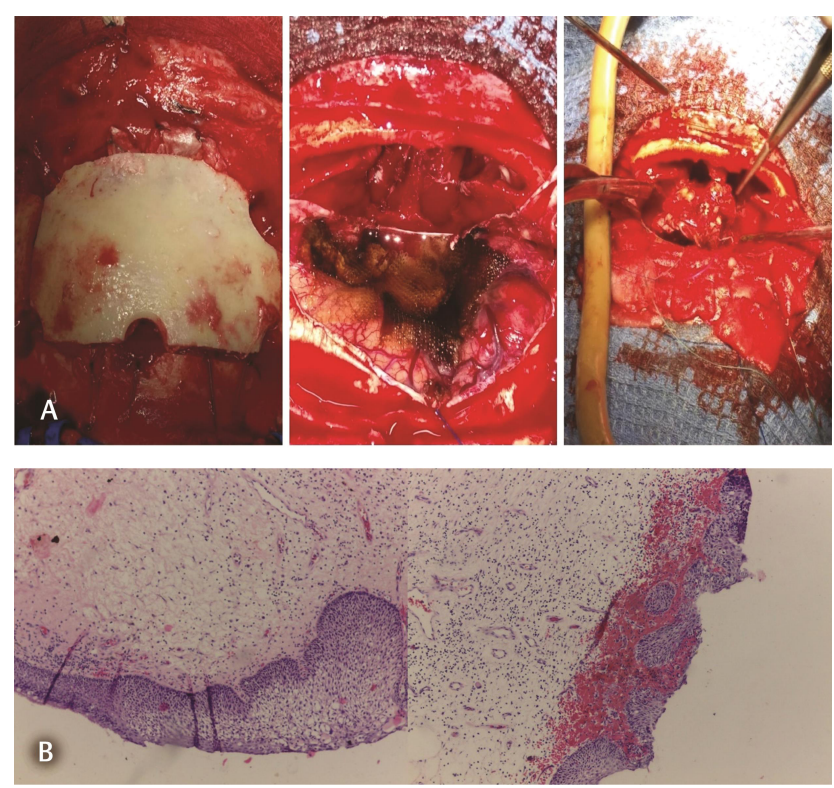

Fig. 2 (A) Intraoperative images of endoscopic endonasal removal of nasal part of the lesion followed by frontal craniotomy and excision. (B) Microscopic view.

\section{Discussion}

Papillomas arising from the Schneiderian membrane (ectodermally derived lining of the sinonasal tract) can be broadly classified into three types: (1) inverted (Ringertz tumor), (2) oncocytic, and (3) fungiform (septal). Of these, fungiform/ septal papilloma is the most common.

In general, sinonasal-type papillomas are common in adults and rare in children, whereas septal papillomas are common in the younger age group. ${ }^{6}$ IPs usually arise from the lateral nasal wall and secondarily extend into the PNSs. They may also arise in the PNS with/without involving the nasal cavity. Schneiderian papillomas are typically unilateral, whereas bilateral papillomas are uncommon. Symptoms vary according to the site of occurrence. Patients present commonly with airway obstruction, epistaxis, symptomatic mass, or pain.

CT and MRI help in the diagnosis and evaluation. CT findings are helpful in characterizing the bony changes including bowing of the bones located near the mass. Contrast CT scan may demonstrate slight enhancement and calcification. MRI helps in determining the extent of the lesion including intracranial and intradural extension

On gross appearance, the IPs can be exophytic, polypoidal, and vascular. Histologically, IPs have an endophytic or inverted growth pattern with markedly thickened squamous epithelial proliferation growing downward into the underlying connective tissue stroma. The epithelium is variegated, composed of squamous, transitional, and columnar cells (all three may be present in a given lesion) with admixed mucocytes (goblet cells) and intraepithelial mucin microcysts.

Differential diagnosis includes sinonasal inflammatory polyps, nonkeratinizing respiratory carcinoma, and verrucous carcinoma.

Squamous cell carcinoma in a case of IP can occur as malignant transformation or as a synchronous or metachronous lesion, and occurs in approximately $9.1 \%$ of all patients. ${ }^{5,7}$

IPs with extension into the intracranial compartment by invasion of bony surfaces with or without malignant transformation are rare. After literature review of IP with intracranial extension, we could identify a total of 12 cases reported till now. Most of these were recurrences of a primary IP, which were resected before extension into the cranial cavity. In majority of the cases, extension was extradural. Our case report is unique as it presented with frontal lobe symptoms and had intradural extension in its first presentation itself.

Treatment includes complete surgical excision, including the adjacent uninvolved mucosa. ${ }^{5.9}$ Recurrence or residual disease is common. Open approaches such as the lateral rhinotomy and midfacial degloving procedures allow increased tumor visualization and more complete resection including maxillectomy, which minimizes the recurrence rates. Intraoperative frozen section may be considered.

\section{Conclusion}

Concurrent IP and squamous cell carcinoma with intradural extension is a rare clinical entity. The reported case is notable 
due to intradural extension and its rare mode of presentation with frontal lobe syndrome

\section{Funding}

None.

\section{Conflict of Interest}

None declared.

\section{References}

1 Melroy CT, Senior BA. Benign sinonasal neoplasms: a focus on inverting papilloma. Otolaryngol Clin North Am 2006; 39(3):601-617, x

2 Buchwald C, Franzmann MB, Jacobsen GK, Lindeberg $\mathrm{H}$. Human papillomavirus (HPV) in sinonasal papillomas: a study of 78 cases using in situ hybridization and polymerase chain reaction. Laryngoscope 1995;105(1):66-71
3 Vrabec DP. The inverted Schneiderian papilloma: a 25-year study. Laryngoscope 1994;104(5 Pt 1) :582-605

4 Lawson W, Le Benger J, Som P, Bernard PJ, Biller HF. Inverted papilloma: an analysis of 87 cases. Laryngoscope 1989;99(11): 1117-1124

5 Tomazic PV, Stammberger H, Habermann W, et al. Aggressive inverted papilloma with intracranial invasion and short malignization time. Skull Base Rep 2011;1(2):111-114

6 Anari S, Carrie S. Sinonasal inverted papilloma: narrative review. J Laryngol Otol 2010;124(7):705-715

7 Ridder GJ, Behringer S, Kayser G, Pfeiffer J. Malignome auf dem Boden invertierter Papillome der Nase und Nasennebenhöhlen. Laryngorhinootologie 2008;87(11):783-790

8 Andersen PJ, Kjeldsen AD, Pedersen AT. Treatment of inverted papilloma with endonasal endoscopic sinus surgery [in Danish]. Ugeskr Laeger 2002;164(37):4283-4287 